\title{
Effect of Joint Commission International Hospitals Accreditation on quality of Health care as Perceived by Nurses
}

\begin{abstract}
Ahlam Gamal Tolba ${ }^{1}$, Fatma Gouda Metwally ${ }^{2}$, and Zienab Ibrahim Ismail ${ }^{3}$
(1)B.Sc. Nursing (2009), (2) Assistant Professor of Nursing Administration, Faculty of Nursing, Zagazig University, Egypt, and (3) lecturer of Nursing Administration, Faculty of Nursing, Benha University, Egypt
\end{abstract}

\begin{abstract}
:
Background: Joint commission international hospitals accreditation aims to improve quality of health care in the international community by providing worldwide accreditation system that include highest standard of quality. Health care organizations can seek accreditation as a selfregulated step for upholding standards in healthcare system, in addition to ensuring compliance and improvement The study aimed to identify the effect of joint commission international hospitals accreditation on quality of health care as perceived by nurses. Study design Descriptive design was utilized to meet the aim of this study. Setting this study was conducted in all inpatients departments at El Araby hospital at Menofia Governorate. The study sample was composed of 206 staff nurses from the above mentioned setting. Two tools were used for data collection; Perceived impact of hospital accreditation outcomes questionnaire and Quality of health care questionnaire. Results The majority of study subjects $(97.6 \%)$ perceived positive outcomes of joint commission international hospitals accreditation, the majority of study subjects (84\%) perceived satisfactory level of quality of health care and total mean score, standard deviation regarding total quality of health care was $(90.05 \pm 21.71)$ that represented $(85.8 \%)$ of the total score. Conclusion This study concluded that there was a significant positive correlation between outcomes of joint commission international hospitals accreditation and total level of quality of health care. The study recommended that increase nurse participation in decision making process to enhance their confidence, patients' satisfaction should be involved as a tool to measure quality.
\end{abstract}

Keywords: Accreditation- Joint commission international accreditation- Quality of care

\section{Introduction:}

Joint Commission International accreditation is the international division of the Joint Commission Resources (JCR) and its mission is to advise, help and continuously improve the international health organizations, health ministries, and public health agencies to reach the highest standards of safety and quality in patient care. JCI provides organization with education, consultation services, international accreditation, and certification, while still accommodating their own religious, cultural and legal factors (JCI, 2017).

The benefits of the joint commission international accreditation process include: creating a safer environment not only for patients but health providers, providing quality training for employees, increasing the involvement and commitment of the leadership and supporting an organization's missions and goals. For these reasons, health care professionals perceive the JCIA as a tool to adapt to the dynamic field of health care 
and to achieve the highest quality (David, 2020).

Accreditation increase patient trust and satisfaction with the setting and quality of services and it is considered a formal evaluation process intends to assess the quality of care and provided services. Its main goal is to assess internal and external mechanism and provide bench marking that could help to improve capacity of hospitals in providing quality care. Some studies assessed accreditation and shown the impact of accreditation on hospitals is significantly positive (Stanford Health Care, 2017).

Accreditation programs have been increasing and spreading throughout the world from developed to developing countries through the past three decades, and today there are several accreditation programs for health care organizations. Although accreditation programs take a variety of forms, accreditation is typically a formal process, by which a recognized bodies, usually a non-governmental organization, assesses and recognizes that a health care organization meets applicable pre-determined and published standards (Rooney, 2019).

Quality of health care is now on the agenda in most health care systems measures are important to document the quality of care, to allow comparisons and judgments, to determine priorities, to support accountability, and to provide transparency in health care. Measuring quality performance gains importance in an era when information flows across borders and individuals and institutes can make comparisons (Donabedian , 2017).

Quality is a complex concept. Thus, its evaluation should be done at different levels of care and from different perspectives of the key stakeholders. Evaluating performance of health care organizations from the stakeholders' perspective is therefore imperative and in specific, nurses' perceptions on quality of care have often been considered an indicative evaluation of the quality of health care provided by these organizations (McGlynn, 2019).

The measurement of healthcare quality is one of the main challenges that face healthcare organizations these days, both politically and in the public eye. Healthcare providers struggle to achieve the quality of care expected by their consumers .Since quality is deemed a key factor in the delivery of patient care initiatives to assess the quality of care delivered to patients have become a worldwide Endeavour. Healthcare quality can be done in different ways, including selfassessment by the healthcare institution, benchmarking between institutions, and external evaluation by an independent organization (Halasa et al., 2020).

Total quality management (TQM) has been defined as an integrated organizational effort designed to improve quality at every level and it is the process to produce a perfect product by a series of measures requires an organized effort to prevent or eliminate errors. TQM is a management approach for an organization, centered on quality, based on the participation of all members and aiming at long-term success through customer satisfaction and benefits to all members of the organization and society. (Seren, et al., 2017).

Nurses play a crucial role in improving quality of health care because they participate in almost every aspect of care delivery, as primarily their responsibility, they influence quality of service, and they 
follow the policies and processes of an organization and the policy makers can gain valuable information by analyzing nursing staff's perceptions about quality of care. So, the perception of healthcare professionals is that accreditation helps improving quality of care (Abolfotouh, et al., 2019).

\section{Significance of the Study}

Joint commission international accreditation helps to improve hospitals systems, processes, operational effectiveness and outcomes. It provides a vision of sustainable quality improvement, supports the effective and efficient use of resources, promotes capacity building, professional development and organizational learning strengthens interdisciplinary team effectiveness and improves communication and collaboration internally and externally. An accreditation certification demonstrates credibility and commitment to quality and accountability and improves organization's reputation among users (Atkinson et al., 2015).

Quality of care is a central concern of any health care entity that makes health policy, and decision-makers at all levels are looking for resources to determine care quality and it is one of the methods that health care organizations use to strengthen and guarantee their efficiency. Health care leaders consider accreditation to be an effective approach for improving the quality of health care. Mission of joint commission international is to improve quality of health care in the international community by providing worldwide accreditation system that include highest standard of safety and quality (Bridi \&Louro, 2014). So, this study aims to identify effect of joint commission international hospitals accreditation on quality of care as perceived by nurses.

\section{Aim of the study:}

This study was aimed to identify effect of joint commission international hospitals accreditation on quality of health care as perceived by nurses.

\section{Research questions}

1. What are the outcomes of joint commission international hospitals accreditation as perceived by nurses?

2. What is the level of total quality of health care as perceived by nurses?

\section{Subject and Method}

\section{Research design:}

Descriptive design was used for carrying out this study

\section{Setting:}

The current study was conducted in all inpatients departments at $\mathrm{El}$ Araby hospital at Menofia Governorate which was affiliated to private sector and accredited at March 2016. The hospital consists of two separate buildings; first building, Medical Surgical and Critical care units with total capacity 300 beds and the second one, Administrative offices

\section{Study subjects:}

Study subjects include all nurses who are available at the study setting at the time of data collection who have at least one year of experience and accept to participate in the study. Their total number was (206) nurses. 


\section{Tools for data collection:}

Two tools were used for data collection in the present study namely; First tool: Perceived impact of hospital accreditation outcomes questionnaire, it is structured questionnaire developed by Pomey, et al. (2004) and it was modified by the investigator to assess outcomes of accreditation as perceived by nurses. It consists of two parts:

Part (1): Personal data about study subjects (age, marital status, education, years of experience, etc).

Part (2): Perceived impact of hospital accreditation outcomes questionnaire, this part includes two domains with (12 items) as follow: degree of staff involvement domain (5items) and benefits of accreditation domain (7items).

\section{Scoring system:}

Subjects' responses were scored on a three point Likert Scale ranged from agree (3), to disagree (1). The level of nurses' perception considered high if the percent score was $>75 \%$, moderate if the total score was ranged from (60-75\%) and low if the percent score < 60\%. (Pomey,et al., 2004).

Second tool: Quality of health care questionnaire. A structured questionnaire developed by (Shortell, et al., 2015) to assess quality of care as perceived by nurses consists of six domains with (35 items) as follows; Quality of care (4 items), Leadership commitment and support (7 items), Strategic quality planning (9 items), Quality management (5 items), Usage of data (5 items) and Human resources utilization (5 items).

\section{Scoring system:}

Subjects' responses were scored on a three point Likert Scale ranged from agree (3), to disagree (1). The level of nurses' perception was considered high if the percent score was $>75 \%$, moderate if the total score was ranged from (60-75\%) and low if the percent score $<60 \%$. (Shortell, et al., 2015)

\section{Pilot study}

A pilot study was carried out in August 2020 to ascertain the clarity and applicability of the study tools. Twenty one nurses were included in the pilot study representing $10 \%$ of total study subjects. It has also served in estimating the time needed for filling the tools. It ranged between (15-30) minutes. No modification was needed so, the pilot study subjects were included in the final sample.

\section{Field work:}

Data collection took about three months from middle of March 2020 to the end of April 2020. The researcher met staff nurses and explained the aim, the nature of the study, and method of filling the questionnaire. This was done individually or through group meetings. Data was collected three days per week in (Saturday, Monday and Thursday) from 10 am to $1 \mathrm{pm}$ in the presence of the researcher to clarify any ambiguity. The researcher distributed the questionnaire sheets to the participated nurses to fill it at their suitable times which determined with the head nurse of each unit. The number of collected questionnaires from staff nurses per day ranged from 5 to 15 sheets. It took from 10 to 20 minutes to complete the questionnaire sheet. 


\section{Validity:}

The study tools were presented to panel of jury for face and content validation. The jury included six experts from four various universities as follows, one assistant professor from Benha University, one professor and 2 assistant professors from Zagazige University, one professor from Tanta University, one professor from Ain Shams University. It took about two months to be completed.

\section{Reliability:}

All tools for data collection were tested for its reliability using test retest reliability and all tools were proved to be strongly reliable. This was done using the assessment of their internal consistency. The reliability proved to be high based on the values of Cronbach alpha coefficients as shown: Joint commission international accreditation outcomes (7.94), quality of health care (0.884).

\section{Ethical considerations}

Before conducting the study, the head nurses and their staff were informed about nature and the purpose of the study, and they were informed that their participation is voluntary and they have the right to withdraw from the study at any time without giving any reason. Informed consent was obtained from each participant of the study. In addition confidentiality and anonymity of the subjects were assured through coding of all data.

\section{Statistical analysis}

Data were collected, tabulated, statistically analyzed using an IBM personal computer with statistical package of social science (SPSS) version 22 where the following statistics were applied. Descriptive statistics: in which quantitative data were presented in the form of Mean, standard deviation (SD), frequency, and percentage distribution. Analytical statistics: Used to find out possible association between studied factors. The used tests of significance included;

- Chi-square test $\left({ }^{\mathrm{x} 2}\right)$ : Was used to study association between two qualitative variables.

- A significance level value was considered when $\mathrm{p}$ - value $\leq 0.05$ and a highly significance level was considered when $\mathrm{p}$ value $\leq 0.001$, while $p$-value $>0.05$ indicated non-significance results.

\section{Results}

Figure (1) illustrates that majority of study subjects (97.6\%) perceived outcomes of joint commission international hospitals accreditation as positive.

Table (1) shows that the benefits of accreditation are the highest outcome of JCI hospitals accreditation with the highest mean scores (19.64 \pm 1.66$)$ While, Total accreditation outcomes were $(33.78 \pm 2.25)$.

Figure (2) shows that the majority of study subjects $(84 \%)$ perceived satisfactory level of quality of health care.

Table (2) illustrate that total mean score and standard deviation regarding total quality of health care was $(90.05 \pm 21.71)$ that represented $(85.8 \%)$ of the total score. In addition to, strategic planning for quality was the highest domain $(23.58 \pm 5.33)$ while, the quality of care was the lowest one (10.28 \pm 2.67$)$. 
Table (3) shows that there was a significant positive relation between outcomes of joint commission international hospitals accreditation and total level of quality of health care.

Table (4) shows that there was no statistically significant relation between Personal characteristics and outcomes of joint commission international hospital Accreditation and outcomes were reported by nurses.
Table (5) shows that there was positive statistically significant relation between personal characteristics and total level of quality of health care regarding their gender, nursing educational qualification and year of experience. Also it shows that the high level was among female staff nurses who had more than or equal (25-35) years old, had bachelor degree of Nursing science, had from (5-15) years of experience in nursing.

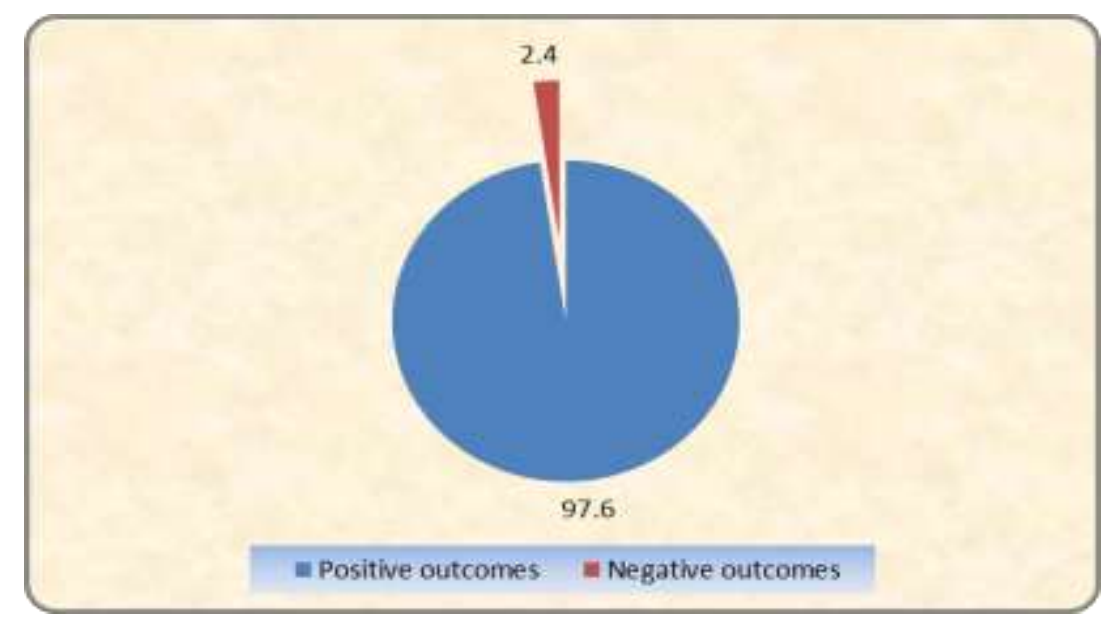

Figure (1): Outcomes of joint commission international hospitals accreditation $(n=206)$

Table (1): Mean scores about outcomes of joint commission international hospitals accreditation $(n=206)$

\begin{tabular}{|l|c|c|c|c||}
\hline Domains & $\begin{array}{l}\text { Total } \\
\text { scores }\end{array}$ & M \pm SD & $\%$ & Ranking \\
\hline \hline Staff involvement & 15 & $14.14 \pm 1.13$ & $94.3 \%$ & 1 \\
\hline Benefits of accreditation & 21 & $19.64 \pm 1.66$ & $93.5 \%$ & 2 \\
\hline Total accreditation outcomes & 36 & $33.78 \pm 2.25$ & $93.8 \%$ & \\
\hline
\end{tabular}




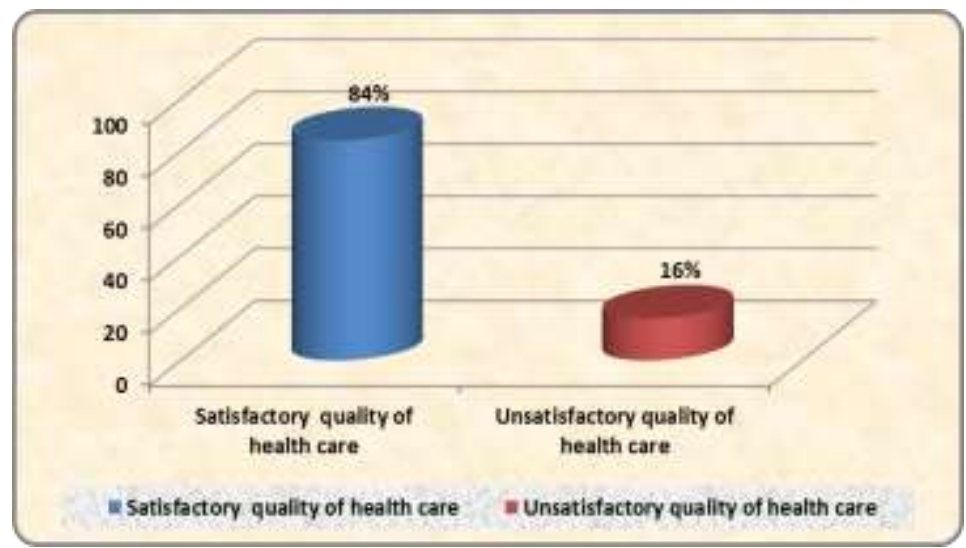

Figure (2) Level of total quality of health care as perceived by study subjects ( $n=206)$

Table (2): Level of total quality of health care domains mean score as perceived by study subjects $(\mathrm{n}=\mathbf{2 0 6})$

\begin{tabular}{||l|c|c|c|c||}
\hline \multicolumn{1}{|c|}{ Domains } & $\begin{array}{c}\text { Total } \\
\text { scores }\end{array}$ & $\mathrm{M} \pm \mathrm{SD}$ & $\%$ & Ranking \\
\hline \hline 1. Quality of care & 12 & $10.28 \pm 2.67$ & $85.7 \%$ & 4 \\
\hline 2.Leadership commitment and support & 21 & $16.91 \pm 5.27$ & $80.5 \%$ & 6 \\
\hline 3.Strategic planning for quality & 27 & $23.58 \pm 5.33$ & $87.3 \%$ & 2 \\
\hline 4.Human resource utilization & 15 & $13.01 \pm 2.86$ & $86.7 \%$ & 3 \\
\hline 5.Quality management & 15 & $13.73 \pm 2.58$ & $91.5 \%$ & 1 \\
\hline 6.Usage of data & 15 & $12.51 \pm 3.42$ & $83.4 \%$ & 5 \\
\hline Total quality of health care & 105 & $90.05 \pm 21.71$ & & $85.8 \%$ \\
\hline
\end{tabular}

Table (3) Relation between total outcomes of joint commission international hospitals accreditation and total level of quality of health care $(n=206)$

\begin{tabular}{|l|c|c|}
\hline \multirow{3}{*}{ Accreditation outcomes } & \multicolumn{2}{|c|}{ Quality of health care } \\
\cline { 2 - 3 } & $\mathrm{r}$ & P value \\
\cline { 2 - 3 } & 0.295 & $0.000^{* *}$ \\
\hline
\end{tabular}


Table (4): Relation between personal characteristics and outcomes of joint commission international hospitals accreditation as perceived by study subjects $(n=206)$

\begin{tabular}{|c|c|c|c|c|c|c|}
\hline \multirow{3}{*}{$\begin{array}{c}\text { personal } \\
\text { characteristics }\end{array}$} & \multicolumn{4}{|c|}{ Total accreditation outcomes } & \multirow{3}{*}{$\mathbf{X}^{2}$} & \multirow{3}{*}{$\mathbf{P}$ - value } \\
\hline & \multicolumn{2}{|c|}{$\begin{array}{l}\text { Positive outcomes } \\
\qquad(n=201)\end{array}$} & \multicolumn{2}{|c|}{$\begin{array}{l}\text { Negative outcomes } \\
\qquad(n=5)\end{array}$} & & \\
\hline & No & $\%$ & No & $\%$ & & \\
\hline \multicolumn{5}{|c|}{ Gender } & \multirow{3}{*}{0.006} & \multirow{3}{*}{0.653} \\
\hline Male & 84 & 41.8 & 2 & 40.0 & & \\
\hline Female & 117 & 58.2 & 3 & 60.0 & & \\
\hline \multicolumn{5}{|c|}{ Age } & \multirow{5}{*}{2.501} & \multirow{5}{*}{0.475} \\
\hline$<25$ years & 10 & 4.9 & 1 & 20.0 & & \\
\hline $25-<35$ years & 151 & 75.1 & 3 & 60.0 & & \\
\hline $35-<45$ years & 31 & 15.5 & 1 & 20.0 & & \\
\hline$\geq 45$ years & 9 & 4.5 & 0 & 0.0 & & \\
\hline \multicolumn{5}{|c|}{ Marital status } & \multirow{3}{*}{0.002} & \multirow{3}{*}{0.720} \\
\hline Married & 159 & 79.1 & 4 & 80.0 & & \\
\hline Unmarried & 42 & 20.9 & 1 & 20.0 & & \\
\hline \multicolumn{5}{|c|}{ Educational qualifications } & \multirow{4}{*}{1.059} & \multirow{4}{*}{0.589} \\
\hline $\begin{array}{c}\text { Diploma degree of } \\
\text { nursing }\end{array}$ & 16 & 7.9 & 2 & 40.0 & & \\
\hline $\begin{array}{c}\text { Associate degree of } \\
\text { nursing }\end{array}$ & 63 & 31.4 & 2 & 40.0 & & \\
\hline $\begin{array}{l}\text { Bachelor degree of } \\
\text { Nursing science }\end{array}$ & 122 & 60.7 & 1 & 20.0 & & \\
\hline \multicolumn{5}{|c|}{ Experience years } & \multirow{5}{*}{2.544} & \multirow{5}{*}{0.467} \\
\hline From $<5$ years & 32 & 15.9 & 1 & 20.0 & & \\
\hline From $5-<15$ years & 146 & 72.7 & 3 & 60.0 & & \\
\hline From $15-<25$ years & 13 & 6.5 & 0 & 0.0 & & \\
\hline More than 25 years & 10 & 4.9 & 1 & 20.0 & & \\
\hline
\end{tabular}


Table (5): Relation between personal characteristics and Total level of quality of health care $(\mathbf{n}=\mathbf{2 0 6})$

\begin{tabular}{|c|c|c|c|c|c|c|}
\hline \multirow{3}{*}{ Personal characteristics } & \multicolumn{4}{|c|}{ Total quality of health care } & \multirow{3}{*}{$\mathbf{X}^{2}$} & \multirow{3}{*}{$\mathbf{P}$ - value } \\
\hline & \multicolumn{2}{|c|}{$\begin{array}{c}\text { Satisfactory } \\
(n=173)\end{array}$} & \multicolumn{2}{|c|}{$\begin{array}{c}\text { Unsatisfactory } \\
(n=33)\end{array}$} & & \\
\hline & No & $\%$ & No & $\%$ & & \\
\hline \multicolumn{5}{|c|}{ Gender } & \multirow{3}{*}{18.52} & \multirow{3}{*}{$0.000 * *$} \\
\hline Male & 76 & 43.9 & 10 & 30.3 & & \\
\hline Female & 97 & 56.1 & 23 & 69.7 & & \\
\hline \multicolumn{5}{|c|}{ Age } & \multirow{5}{*}{16.14} & \multirow{5}{*}{$0.000 * *$} \\
\hline$<25$ years & 11 & 6.4 & 0 & 0.0 & & \\
\hline $25-<35$ years & 143 & 82.7 & 11 & 33.3 & & \\
\hline $35-<45$ years & 19 & 10.9 & 13 & 39.4 & & \\
\hline$\geq 45$ years & 0 & 0.0 & 9 & 27.3 & & \\
\hline \multicolumn{5}{|c|}{ Marital status } & \multirow{3}{*}{14.89} & \multirow{3}{*}{$0.000 * *$} \\
\hline Married & 152 & 87.9 & 11 & 33.3 & & \\
\hline Unmarried & 21 & 12.1 & 22 & 66.7 & & \\
\hline \multicolumn{5}{|c|}{ Educational qualifications } & \multirow{4}{*}{25.46} & \multirow{4}{*}{$0.002 * *$} \\
\hline $\begin{array}{l}\text { Diploma degree of } \\
\text { nursing }\end{array}$ & 10 & 5.8 & 7 & 21.2 & & \\
\hline $\begin{array}{l}\text { Associate degree of } \\
\text { nursing }\end{array}$ & 60 & 34.7 & 4 & 12.1 & & \\
\hline $\begin{array}{l}\text { Bachelor degree of } \\
\text { Nursing science }\end{array}$ & 103 & 59.5 & 22 & 66.7 & & \\
\hline \multicolumn{5}{|c|}{ Experience years } & \multirow{5}{*}{14.31} & \multirow{5}{*}{$0.000 * *$} \\
\hline From $<5$ years & 23 & 13.3 & 10 & 30.3 & & \\
\hline From $5-<15$ years & 140 & 80.9 & 9 & 27.3 & & \\
\hline From $15-<25$ years & 5 & 2.9 & 8 & 24.2 & & \\
\hline More than 25 years & 5 & 2.9 & 6 & 18.2 & & \\
\hline
\end{tabular}

\section{Discussion:}

Accreditation is one of the influential mechanisms for assessing the performance of health care organization and improving the quality of health care services, accreditation is typically a formal process by which a recognized body assesses and recognizes that a health care organization meets applicable predetermined and published standard. (Jaafaripooyan et al., 2019).

Regarding outcomes of joint commission international hospitals accreditation the current study finding illustrates that the majority of 
study subject's perceived outcomes of joint commission international hospitals accreditation as positive. These findings mean that the process of accreditation puts the hospital on the right track. It helps nurses do the right thing in the right way for the right patient in the right time from the first time and every time and this finding appear to be due to joint commission international accreditation is very important and The JCI accreditation standard affects the care because it is evidencebased and people implement it in the right, and scientific way, under the supervision of surveyors who are considered experts in their fields. When standards are implemented correctly it will eventually improve the service.

This study finding was similar with Pomey et al, (2014) who studied "Accreditation: a tool for organizational change in hospitals" And El-Jardali et al., (2018) who studied "The impact of hospital accreditation on quality of care: Perception of Lebanese nurses" and they reported that the majority of nurses perceived positive outcomes of joint commission international hospitals accreditation.

Regarding Mean scores about Outcomes of Joint commission international hospitals accreditation, the current study findings shows that benefits of accreditation had the highest mean scores. These result may be due to health care providers were more familiar with the joint commission international hospitals accreditation process after the formal survey and were more involved in the quality improvement process and this lead to overall improvement of provided health care.

The current study finding was in the same line with a study carried out by Collopy, et al (2019) who studied "Clinical indicators in accreditation: An effective stimulus to improve patient care" and Al Attal, (2019). Who examined "Factors affecting the implementation of joint commission international standards in United Arab Emirates hospitals" and they reported that benefits of accreditation had the highest mean scores. Also, this finding was matched with Brubakk et al. (2018) who examined " A systematic review of hospital accreditation: the challenges of measuring complex intervention effects " and reported that highest mean scores was given for the benefits of accreditation.

However, this study finding was in disagreement with Greenfield\& Braithwaite (2019) who examined" Developing the evidence based for accreditation of healthcare organizations: A call for transparency and innovation, Quality and Safety in Health Care "who found that the highest mean percent score was for the staff involvement.

Concerning level of total quality of health care as perceived by study subjects the current study finding illustrates that the majority of study subjects perceived satisfactory level of quality of health care. This finding appears to be due to quality of health care designed to ensure both compliance and improvement in all services by which provided in the hospital.

This result goes in hand with results of Grimmer \& Moss, (2019) who studied "The development, validity and application of a new instrument to assess the quality of discharge planning activities from the community perspective" and they explained that nurses who constitute the majority of total health care employees were satisfied with the level of quality.

Additionally, the study conducted by Qureshi \& Ullah, (2017) about "The trend of hospital accreditation in the Kingdom of Saudi Arabia" Highlighted that the majority of nurses perceived high level of quality of health care. 
Regarding quality of health care domains, mean score. The present study reported that total quality of health care was $(90.05 \pm 21.71)$ of the total score and this may be due to quality of care is a fundamental concern of every health care organization that makes health policy and decision makers at all levels seek tools to evaluate the level of care and the hospital considered one of the tools that health care organizations adopt to enhance and assure their quality.

This result was parallel with the results of Shortell, et al (2015) who conducted a study about "Assessing the impact of total quality management and organizational culture on multiple outcomes of care" they clarify that the highest mean score and standard deviation for total quality of healthcare. In addition to, this result was consistent with the study conducted by Bennett (2019) in "Assessing the impact of continuous quality improvement on clinical practice: What it will take to accelerate progress" and showed that total mean score, standard deviation for quality of health care.

Concerning to relation between total outcomes of joint commission international hospitals accreditation and total level of quality of health care, the present study shows that there was a significant positive relation between outcomes of joint commission international hospitals accreditation and total level of quality of health care.

This may be due to Health care leaders consider joint commission international hospitals accreditation an effective approach for developing health care quality and the interest of any health care organization to obtain accreditation as a tool to improve the quality of their services. So, accreditation helps organizations to achieve a competitive advantage by showing that they are open for external evaluations and increasing quality level.

As marked from the study findings. These findings were documented in previous studies as the study findings of Larson\& Muller, (2019) who studied "Managing the quality of health care" and Lee, (2017) who conducted "Assessing the factors influencing continuous quality improvement implementation: Experience in Korean hospitals" and they revealed that there are positive relation between outcomes of joint commission international accreditation and total quality of health care.

Concerning relation between personal characteristics and outcomes of joint commission international hospitals accreditation, the present study shows that there was no statistically significant relation between personal characteristics and outcomes of joint commission international hospitals accreditation. This findings appears to be due to outcomes of joint commission international hospitals accreditation depends on certain standards and not related to personal characteristics and all staff nurses should be aware of these standards whatever their features and they should know about JCI and what they need to know.

The current study findings was in agreement with Manzo, et al (2017) who conducted a study named" Nursing in the hospital accreditation process: Practice and implications in the work quotidian" and revealed that outcomes of joint commission international accreditation (JCI) not related to personal characteristics.

In addition to, this finding matched with the study conducted with Menachemi, et al., (2018) "Quality of care in accredited and non accredited ambulatory surgical centers" and 
they reported that there was no statistically significant relation between personal characteristics and outcomes of joint commission international accreditation. Morever, the study conducted by Lawrence, (2019) about" Accreditation: a tool for organizational change in hospitals" showed that no relation between personal characteristics and outcomes of joint commission international accreditation.

However, this finding was in contrary with Shaker, (2018) who revealed that there was statistically significant relation between personal characteristics and outcomes of joint commission international accreditation.

Regarding relation between personal characteristics and Total level of quality of health care, the current study findings showed that there was positive statistically significant relation between personal characteristics and total level of quality of health care.

These findings may be appear due to engaging in any quality improvement programmed needs enough mature nurses which well trained before accreditation ,enough time and sufficient education and training in order to get employees prepared and increase their awareness and commitment. Nurses staff culture changed towards quality issues if given sufficient experience, sufficient time to prepare, train and educate nurses on these standards, and provided them with all supplies and needs, will improve the service with enough manpower.

In similarity with this finding, the study findings of Pongpirul, et al (2016) who conducted study about" Comparison of health care professionals' and surveyors' opinions on problems and obstacles in implementing quality management system in Thailand" and Heidemann, (2018) who examined" Hospital performance trends on national quality measures and the association with joint commission accreditation" they revealed that there was positive statistically significant relation between personal characteristics and total quality of health care.

However, this finding was in contrary with Soltani et al., (2019) who made study about " Breaking through barriers to TQM effectiveness: Lack of commitment of upperlevel management. Total Quality Management" and Abd El Ghaffar, (2018) who examined" The Impact of Accreditation on patient Safety and quality of Care as Perceived by nursing staff in a university hospital in Saudi Arabia " and they concluded that there wasn't statistically relation between personal characteristics and total quality of health care.

\section{Conclusion:}

The majority of study subjects perceived positive outcomes of joint commission international hospitals accreditation and the majority of study subjects perceived satisfactory level of quality of health care. Also, this result revealed that there was a statistically positive correlation between all dimensions of quality of health care. There was a significant positive correlation between outcomes of joint commission international hospitals accreditation and total level of quality of health care.

\section{Recommendations:}

Administrators are recommended to involve nurses in the decision-making process to enhance their confidence and commitment to what needs to be done.:

- Interviewing patients about their experience needs to be considered in the future in order to understand the reasons for their responses and to improve the process of accreditation. 
- Continuous assessing factors that affect quality in order to keep continuous improvement in quality of health care.

- For the most effective quality of health care, there should be collaboration between the nurses' managers and the nurses through effective communication and education.

\section{References}

Abd El Ghaffar, A., (2018). The Impact of Accreditation on patient Safety and quality of Care as Perceived by nursing staff in a university hospital in Saudi Arabia, pp (9598).

Aboulfotoh, Mostafa, Mohamed, Nawal, Salama, Ahmed (2019). Nursing perception toward impact of JCI accreditation and quality of care in tertiary care hospital, Central Saudi Arabia. Date of retrieval:2 Aug 2019 fromhttps://www.researchgate.net/publication/2 61358412 Nursing perception Toward Impact of JCI Accreditation and Quality of care in a Tertiary Care Hospital Central Saudi Arabia.

Al Attal, Z., (2019). Factors affecting the implementation of joint commission international standards in United Arab Emirates hospitals University of Salford, (master's thesis, 2019).

Atkinson, Melanie; Tuekel \& Marian., (2015). Overcoming Barriers to Research in a Magnet Community Hospital. Journal of Nursing Care Quality, 23(4), pp(362-368).

Bennett, S., Franco, L. M., Kanfer, R., \& Stubblebine, P., (2019). The Development of Tools to Measure the Determinants and Consequences of Health Worker Motivation in Developing Countries, pp (222-228).
Bridi EC \& Louro, TQ. (2014). Implication of alarm fatigue for safety of the patient, pp (22-40).

Campbell, Roland \& Buetow, (2018). Defining Quality of Care. Retrieved February 8, 2019, from https://jotsheet.wordpress.com/2019campbe 11-rolandbuetow- 2000-defining-qualityof-care/

Brubakk, (2018). A systematic review of hospital accreditation: the challenges of measuring complex intervention effects, $\operatorname{pp}(111-115)$.

Collopy, B. T., (2019). Clinical indicators in accreditation: An effective stimulus to improve patient care. International Journal for Quality in Health Care, 12(3), pp( 211216).

Donabedian, A., (2017). Evaluating the quality of medical care. The Milbank Memorial Fund Quarterly, 44(9), pp( 166220).

El-Jardali, (2018). The impact of hospital accreditation on quality of care: perception of Lebanese nurses. International Journal for Quality in Health Care, $\mathrm{P}(363-371)$.

Joint Commission International, (2017). Joint Commission International Accreditation Standards for Hospitals. Oakbrook, IL: Joint Commission on Accreditation of Health care

Grimmer, K., \& Moss, J., (2019). The development, validity and application of a new instrument to assess the quality of discharge planning activities from the community perspective. International Journal for Quality in Health Care, Pp(109116). 
Greenfield, D., Braithwaite, J., (2019). Health sector accreditation research: a systematic review. Quality Health Care, $\operatorname{Pp}(72-83)$

Jaafaripooyan, E., Agrizzi, D., \& AkbariHaghighi, F., (2019). Healthcare accreditation systems: Further perspectives on performance measures. International Journal for Quality in HealthCare, 23(6), pp (645-656).

Halasa, Y., Zeng, W., Chappy, E., \& Shepard, D. (2020): Value and impact of international hospital accreditation: A case study from Jordan. Eastern Mediterranean Health Journal, 21(2), pp (90-99).

Larson, J., \& Muller, A., (2019). Managing the quality of health care. Journal of Health and Human Services Administration, 25(9), pp (261-280).

Lee, T., Leung, H. \& Chan, K., (2017). Improving quality management on the basis of ISO 9000. TQM Magazine, 17(7), pp(8894).

Manzo, B., Ribeiro, H., Brito, M., \& Alves, M,. (2017). Nursing in the hospital accreditation process: Practice and implications in the work quotidian. Revista Latino-Americana de Enfermagem, 20(1), pp (151-158).

McGlynn, E., (2019). Six challenges in measuring the quality of health care. Health Affairs, 16(3), pp (7-21).

Menachemi, N., Chukmaitov, A., Brown, S., Saunders, C., \& Brooks, R., (2018). Quality of care in accredited and non accredited ambulatory surgical centers. Joint Commission Journal on Quality and Patient Safety, 34(9), pp (546-551).
Pomey,MP., (2004). Accreditation ,atool for organizational change in hospitals.Int Health care quality assurance, pp (17-113).

Pomey, M. P., Lemieux,Charles, L., Champagne, F., Angus, D., Shabah, A., \& Contandriopoulos, A. P., (2014). Does fccreditation stimulate change? A study of the impact of the accreditation process on Canadian healthcare organizations. Implementation Science, 5(5), pp (31).

Qureshi, A. Z., \& Ullah, R., (2017). The trend of hospital accreditation in the Kingdom of Saudi Arabia. Saudi Medical Journal, 33(17), pp (1350-1351). Retrieved from www.smj.org.sa

Pongpirul, K., Sriratanaban, J., Asavaroengchai, S., Thammatach-Aree, J., \& Laoitthi, P. (2016). Comparison of health care professionals' and surveyors' opinions on problems and obstacles in implementing quality management system in Thailand: A national survey. International Journal for Quality in health Care, 18(5), pp( 346-351).

Rooney, A. L., (2019). Licensure, accreditation, and certification: Approaches to health services quality. Retrieved from United States Agency for International Development.

Seren, S., Baykal, U., Nurs Scholarsh, (2017). Relationships between change and organizational culture in hospitals, $\mathrm{Pp}($ 39:181).

Shaker, (2018). Organizational culture, critical success factors, and the reduction of hospital errors. International Journal of Production Economics, 106(2), pp (9368392). 
Shortell , SM., (2015). Assessing impact of continuous quality improvement/ total quality management/concept versus implementation. $\quad$ PP(377-401), Retrieved from

http://www.stanfordhealthcare.org/healthcare-professionals/ nursing/ quality safety/purposeful-rounding.hrmll.( at 12 february 2019).

Soltani, E., Lai, P., \& Gharneh, N. (2019): Breaking through barriers to TQM effectiveness: Lack of commitment of upper-level management. Total Quality Management, 16(8), pp (1009-1021).

Stanford Health Care, (2017). Nursing quality and safety purposeful rounding. Retrived from https://www.stanford health

care.org/health-care professionals/nursing/qualitysafety/purposef ul rounding. alkhlfyt thdf alljnt almshtrkt laet 
ادراك طلاب ومعلمي التمريض تجاه حقوق طلاب التمريض وعلاقتها برضاء طلاب التمريض

$$
\text { أحلام جمال طلبه - فاطمة جودة متولي - زينب إبر اهيم اسماعيل }
$$

تعد جودة الرعاية الصحية أحد التحديات الرئيسية التي تواجه مؤسسات الرعاية الصحية هذه الأيام ، سواء

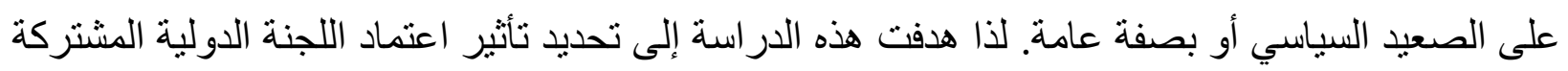
للمستشفيات على جودة الرعاية الصحية من وجهة نظر الممرضات .حيث أجريت الدراسة في جميع الأقسام

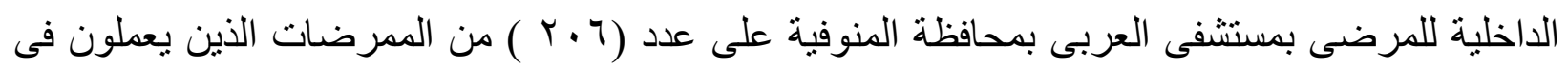
مكان الدر اسة. وقد لخصت الدراسة بوجودعلاقة إرتباط ايجابى ذو دلالة إحصائية بين نتائج اعنماد اللجنة الدولية المشتركة للمستشفيات ومستوي جودة الرعاية الصحية. وقد اوصت الدراسة بتشجيع النمو المهني للعاملين في التمريض من خلال توفير بر امج تدريبية لتعزيز نمو هم في مهنتهم من خلال التمكين و التدريب. 